\title{
Hardiness Is Negatively Related to Gambling
}

\author{
Salvatore Maddi \\ University of California, Irvine, Irvine, USA \\ Email:srmaddi@uci.edu
}

Received 25 June 2016; accepted 23 August 2016; published 26 August 2016

Copyright (C) 2016 by author and OALib.

This work is licensed under the Creative Commons Attribution International License (CC BY).

http://creativecommons.org/licenses/by/4.0/

(c) (i) Open Access

\begin{abstract}
In previous research, hardiness has been shown to be positively related to good performance, well-being, and sense of fulfillment. The relevant samples have included college students, working adults, and military and safety personnel. The present study expands this pattern, by showing that hardiness is negatively related to gambling behavior. In this context, gambling behavior is considered an example of avoidance (rather than problem-solving) coping with the ongoing stresses of living.
\end{abstract}

Keywords

Hardiness, Gambling, Regressive Coping, Transformational Coping

Subject Areas: Psychology

\section{Introduction}

Hardiness has been conceptualized as the personality pattern of attitudes and strategies that helps people turn stressful circumstances from potential disasters into growth opportunities instead (Maddi, [1], [2]). Specifically, the Hardy Attitudes are the 3Cs of commitment, control, and challenge. Commitment is the belief that no matter how bad things get, it is best to remain involved with the relevant people and circumstances, rather than back off into isolation. Control is the belief that even in difficult circumstances, it is best to keep trying to have an effect on outcomes, rather than slipping into powerlessness. And challenge is the belief that life is by its nature stressful, and that working on these stresses leads you to learn and grow in the process. Lots of research has shown that the 3Cs are positively interrelated, and that the combination of them helps people grow and develop (Maddi, [2]; Maddi \& Khoshaba, [3]). Indeed, the Hardy Attitudes seem to provide the courage and motivation to do the hard work of turning stresses to advantage. This hard work involves the Hardy Strategies of problem-solving (rather than avoidance) coping, socially-supportive (rather than conflictful) interactions, and beneficial (rather than over-indulgent) self-care. In this process, the Hardy Attitudes are positively related not only to the Hardy Strategies, but also to performance enhancement, positive moods, and health (Maddi, [2]; Maddi \& Khoshaba, [3]). In the studies already mentioned, it is clear that hardiness was measured first, and the dependent variables 
were measured later. This suggests that hardiness influences the measures of performance, mood, and health, rather than the other way around.

Of particular relevance to the present study are four recent studies. In one of them (Maddi, Matthews, Kelly, Villarreal, \& White, [4]), hardiness was measured in a cadre of West Point Military cadets before they started their academy training. It was their performance and retention totals at the end of their first year of training that showed the positive correlations with hardiness. These positive correlations were also shown to have persisted through the entire four years of the cadets' training (Maddi, Matthews, Kelly, Villarreal, \& Bach, [5]). In another study (Maddi, Harvey, Khoshaba, Fazel, \& Resurreccion, [6]), a large sample of college undergraduates went through a hardiness training course, which showed not only that their hardiness levels increased during the course, but also that their GPAs increased over the ensuing years of school until graduation. In the fourth study (Bartone, Hystad, Jarie Eid, and Brevik [7]), there was shown to be a negative correlation between hardiness and alcohol abuse in a sample of Norwegian military defense personnel. Alcohol abuse can certainly be considered a sign of avoidance coping.

Another behavior that can well be conceptualized as avoidance (rather than problem-solving) coping, and over-indulgent (rather than beneficial) self-care is gambling (Maddi, [2]). It is probable that when someone engages regularly in gambling, he/she is trying to avoid the ongoing stresses and pressures of their everyday life. This is likely to be true even if one of the stresses is that their life is boring. So, instead of using hardiness as a way to transform the stresses into growth opportunities by the learning and changes that are made, the gambler is just trying to avoid the stresses and negative feelings that are involved. And, when gambling becomes a regular way of life, rather than an occasional event, the person is also engaging in over-indulgent self-care. After all, it is unlikely that gambling may be a constructive technique for making money, as what is involved is more a matter of luck than of ongoing growth in functioning.

There are empirical studies of gambling that are consistent with this position. For example, Stemarie, Gupta, \& Derevensky, [8] found that adolescent gamblers report more anxiety and social stress compared to nongamblers. Further, Hayatbakhsh, Clavarino, Williams, Bor, and Najman [9] found that adolescents who smoke, externalize problems, perform poorly in high school, or experienced childhood sexual abuse are more likely to be gambling when they are 21 years of age. Also, Lalande, Bastille-Denis, Savard, Jacques, Leclerc, \& Giroux [10] report that by comparison with gamblers, those who do not gamble show optimism, expectation of success, and well-being. There is certainly empirical evidence that gambling involves avoiding stresses and trying to find an easy way out. Taking all this into account, the hypothesis of this study is that there is a negative relationship between hardy attitudes and gambling.

\section{Method}

\subsection{Participants}

The sample for this study was 196 voluntary participants, 110 of whom were undergraduates at the University of California, Irvine, and 86 of whom were adults from the general public recruited through a Craigslist advertisement. As compensation for completing this study's surveys, the undergraduates received extra credit in one of their courses, and the participants recruited through Craigslist were given either a five-dollar American, or Starbucks gift card. The sociocultural backgrounds of the subjects was 38\% Caucasians, 23\% Asians, $12 \%$ Latinos, 14\% African-American, 3\% Native American, 4\% Middle Eastern, and 4\% Multi-Racial. Also, the sample contained 56 males, and 93 females. Further, the age in the sample ranged from 18 to 55, and averaged at 25 .

\subsection{Measures}

Participants were asked to complete the Personal Views Survey III-R (PVS III-R) which is the latest, and validated measure of hardy attitudes (Maddi, [2]), and the South Oaks Gambling Screen (SOGS), which is a frequently used measure of gambling (Lesieur \& Blume, [11]).

The PVS III-R is an 18 item questionnaire, including positively and negatively worded items, which are answered on a 4-point Likert scale stemming from "Not at all true" to "Completely true". There are many research studies showing that this scale has adequate reliability and validity. In one of these studies, Sinclair and Tetrick [14] showed that factor analyses of the item scores yielded three positively-related first-order factors consistent with the conceptualization of commitment, control, and challenge, and that a second-order factor emerged con- 
sistent with the conceptualization of total hardiness. Positively-worded item examples are, for commitment: "By working hard, I am always able to achieve my goal”, for control: "When I make plans, I'm certain I can make them work", and for challenge: "Changes in routine provoke me to learn". In the present sample, the Cronbach Alpha reliability coefficient for the total hardiness score was 0.75 .

The SOGS is a 16 item questionnaire that refers to the extent of gambling activities. Specifically, items require subjects to indicate how often they gamble, what is the largest amount of money they have gambled in one day, whether they have lost time from work or school due to gambling, and whether they could stop gambling. The item answers are combined to produce an overall measure of the extent of the subject's gambling, from none to mild, moderate, or extreme. This SOGS was used in an epidemiological survey by the New York State Office of Mental Health (Lesieur, \& Blume, [12], [13]), showing that 1.4\% of the adult population of New York had scores of 5 or higher on the SOGS, and were therefore classified as probable gamblers. This base rate for the general population is similar to that found in earlier studies. In the present study, the Cronbach Alpha reliability coefficient for the SOGS was 0.96 .

\subsection{Statistical Analysis}

Correlational analyses were conducted in producing all of the findings in this study.

\section{Results and Discussion}

The correlation in the 196 subjects in this study between the hardiness and gambling scores was -0.562 , which is significant beyond the 0.001 level. As expected, this shows that the stronger one's hardy attitudes of commitment, control, and challenge, the less likely one is to engage in gambling behaviors. This is consistent with the conceptualization of hardiness (Maddi, [2]) as the courage and motivation to carry out the difficult work of turning stressful circumstances from potential disasters into growth opportunities, rather than engaging in avoidance of the stresses in hopes of feeling better. Indeed, the subjects highest in hardiness tended to emphasize that they were too involved in the circumstances of their everyday lives to waste time and money on gambling. This shows transformational coping with regard to life's stresses. In contrast, the subjects lowest in hardiness considered gambling a useful distraction from their ongoing problems that were undermining them. In contrast, this expresses regressive coping with life's stresses.

By now, there is much research and consulting data showing that hardiness can be trained, and that this training helps to improve not only the Hardy Attitudes, but also improves performance, mood, and health (e.g., Maddi, [2]; Maddi, Kahn \& Maddi, [14]; Maddi \& Khoshaba, [3]; Maddi, Khoshaba, Jensen, Carter, Lu \& Harvey, [15]; Maddi, Harvey, Khoshaba, Fazel \& Resurreccion, [6]).

These, and the results of the present study indicate the potential value of hardiness training in the effort to reduce gambling behavior.

Although this study opens the way to showing how hardiness helps people turn the stressful circumstances they are experiencing from potential disasters into growth opportunities instead, additional research needs to be done to further support this hypothesis. In particular, it would be useful to test the hardiness and achievement levels of people whose lives are committed to gambling, and compare this to people who never gamble at all.

\section{References}

[1] Maddi, S.R. (1987) Hardiness Training at Illinois Bell Telephone. In: Opatz, J.P., Ed., Health Promotion Evaluation, National Wellness Institute, Stevens Point, 101-115.

[2] Maddi, S.R. (2002) The Story of Hardiness: Twenty Years of Theorizing, Research, and Practice. Consulting Psychology Journal, 54, 175-185. http://dx.doi.org/10.1037/1061-4087.54.3.173

[3] Maddi, S.R. and Khoshaba, D.M. (1994). Hardiness and Mental Health. Journal of Personality Assessment, 63, 265274. http://dx.doi.org/10.1207/s15327752jpa6302_6

[4] Maddi, S.R., Matthews, M.D., Kelly, D., Villarreal, B. and White, M. (2012) Hardiness and Grit Predict Performance and Retention of USMA Cadets. Military Psychology, 24, 19-28. http://dx.doi.org/10.1080/08995605.2012.639672

[5] Maddi, S.R., Matthews, M.D., Kelly, D., Villarreal, B. and Bach, S. H. (2015) The Continuing Role of Hardiness and Grit in Performance and Retention in West Point Cadets. In Preparation.

[6] Maddi, S.R., Harvey, R.H., Khoshaba, D.M., Fazel, M. and Resurreccion, N. (2009) Hardiness Training Facilitates 
Performance in College. Journal of Positive Psychology, 4, 566-577. http://dx.doi.org/10.1080/17439760903157133

[7] Bartone, P.T., Hystad, S.W., Eid, J. and Brevik, J. I. (2012), Psychological Hardiness and Coping Style as Risk/ Resilience Factors for Alcohol Abuse. Military Medicine, 177, 517-524. http://dx.doi.org/10.7205/MILMED-D-11-00200

[8] Stemarie, C., Gupta, R. and Derevensky, J.L. (2008) Anxiety and Social Stress Related to Adolescent Gambling Behavior. International Center for Youth Gambling and High-Risk Behaviors (McGill University).

[9] Maddi, S.R., Kahn, S. and Maddi, D.L. (1998) The Effectiveness of Hardiness Training. Consulting Psychology Journal, 50, 78-86. http://dx.doi.org/10.1037/1061-4087.50.2.78

[10] Hayatbakhsh, M.R., Clavarino, A.M., Williams, G.M., Bor, W. and Najnan, J.M. (2013) Early Life Course Predictors of Young Adults' Gambling. International Gambling Studies, 1, 19-36. http://dx.doi.org/10.1080/14459795.2012.700941

[11] Laland, D.R., Bastille-Denis, S., Savard, C., Jacques, C., Lecdlerc, M. and Giroux, I. (2013) Another Step toward Identifying Potential Protective Factors against Problem Gambling. International Gambling Studies, 1, 19-36.

[12] Lesieur, H.R. and Blume, S.B. (1987) The South Oaks Gambling Screne (SOGS): A New Instrument for the Identification of Pathological Gamblers. American Journal of Psychiatry, 144, 1184-1188. http://dx.doi.org/10.1176/ajp.144.9.1184

[13] Lesieur, H.R. and Blume, S.B. (1993) Revising the South Oaks Gambling Screen in Different Settings. Journal of Gambling Studies, 9, 213-219. http://dx.doi.org/10.1007/BF01015919

[14] Sinclair, R.R. and Tetrick, L.E. (2000) Implications of Item Wording for Hardiness Structure, Relation with Neuroticism, and Stress Buffering. Journal of Research in Personality, 34, 1-25. http://dx.doi.org/10.1006/jrpe.1999.2265

[15] Maddi, S.R. and Khoshaba, D.M. (2002) Hardiness Training for Resiliency and Leadership. In: Paton, D., Violanti, J.M. and Smith, L.M., Eds., Post-Traumatic Psychological Stress: Individual, Group and Organizational Strategies for Resilience, Charles C. Thomas, Springfield, 43-58.

\section{Submit or recommend next manuscript to OALib Journal and we will provide best service for you:}

- Publication frequency: Monthly

- 9 subject areas of science, technology and medicine

- Fair and rigorous peer-review system

- Fast publication process

- Article promotion in various social networking sites (LinkedIn, Facebook, Twitter, etc.)

- Maximum dissemination of your research work

Submit Your Paper Online: $\underline{\text { Click Here to Submit }}$

Contact Us: service@oalib.com 